Article

\title{
Electromagnetic Analysis and Performance Investigation of a Flux-Switching Permanent Magnet Machine
}

\author{
Muhammad Azeem and Byungtaek Kim * (iD \\ Department of Electrical Engineering, Kunsan National University, Gunsan-si 54150, Korea \\ * Correspondence: btkim@kunsan.ac.kr; Tel.: +82-063-469-4744
}

Received: 8 August 2019; Accepted: 29 August 2019; Published: 1 September 2019

\begin{abstract}
This paper aims to present a general and effective analytical approach to calculate the air gap flux density and the back electromotive force (EMF) of a flux-switching permanent magnet (FSPM) machine. The proposed analytical expression of the air gap flux density is based on an improved air gap permeance function considering the geometries of slotted stator core pieces and magnets between stator teeth as well as the salient rotor poles. The back EMF equation is accurately derived using the proposed air gap flux density equation expressed in terms of practical machine dimensions and thus it provides the key design factors as well as details of the back EMF production mechanism. To validate the proposed analytical expressions, they are applied to the case study of a 12-slot 10-pole FSPM machine, and the finite element analysis results confirm the analytical predictions. Besides, for the proposed analytical model, the effects of the machine's geometries on back EMF characteristics are investigated. The investigation shows that the ratio of rotor slot opening to slot pitch has a significant effect on the back EMF, and its optimal value is suggested. The proposed equations also provide a mean to choose the slot and pole combinations to obtain a higher power density.
\end{abstract}

Keywords: flux-switching machine; air gap flux density; back EMF; modulation flux; performance investigation; finite element analysis

\section{Introduction}

A flux-switching permanent magnet (FSPM) machine not only has a different structure but also uses a different operating principle compared to conventional PM machines. This machine uses modulation flux, which produces magnetic gear effects and thus is suitable for applications requiring low speed and high torque. Since both the armature windings and the magnets are mounted on the stator side, it presents the additional advantages of mechanically stable magnets and higher heat dissipation capability.

Since the proposal of the FSPM machine about 60 years ago [1], several research accomplishments have been intermittently reported [2-4]; however, intensive research has been actively carried out in the recent 10 years worldwide [5]. An FSPM machine with modular and segmented rotor was described in references [6,7], which showed that the modular rotor significantly reduced iron losses. In another study [8], segmented magnets were used to enhance the torque and to reduce the surface flux leakage. In addition, this technique also reduces the eddy current loss in the magnets. To control the air gap field, hybrid flux-switching was applied in a study [9]. The comparison of flux-switching topologies with field winding and PMs is discussed in reference [10], which concludes that the power density of a machine having magnets is much better than the field winding structure. In order to reduce the cost and increase the torque density, the E-core structure of a flux-switching machine was proposed, showing that the new structure significantly reduced the magnet, maintaining the same 
electromagnetic performance [11]. The basic principle of the torque production mechanism based on spatial harmonic was explained in reference [12].

While suggestions for new structures of the FSPM machine have been numerous, studies on analysis methods have been relatively less. For the analysis of electrical machines, it is essential to investigate the air gap magnetic flux density, and the magnetic flux density is greatly related to the geometry of the air gap, which can be even or uneven. An FSPM machine, one of the doubly salient pole machines, utilizes the modulation flux generated by air gap length variation as the rotor rotates. Thus, from the point of view of the operation principle, the FSPM machines differ from the general doubly salient machines such as the reluctance-machines. Furthermore, the FSPM machine has magnets between the stator cores, which makes the geometry of the air gap very complicated and the calculation of the magnetic flux density more difficult. For the analysis of such an FSPM motor, in reference [13], the air gap flux densities were obtained by expressing the uneven air gap with various lumped magnetic reluctance networks. However, this method requires a lot of effort to construct each magnetic circuit for various rotor positions and extract the flux component contributing to the back electromotive force (EMF) production from the air gap flux obtained from each circuit.

On the other hand, the air gap permeance function that represents the magnetic length distribution (in fact, its reciprocal) in the air gap is very useful for expressing the air flux density in an analytical form, especially for uneven gaps [14]. In reference [15], the air gap magnetic flux density and the back EMF equation were presented by using this air gap permeance function for the analysis of the FSPM motor; however, they were not detailed enough to allow precise calculations, because the primary concern of the study was the overall design of the FSPM machine, not an accurate analysis. Especially, in the flux density equation, the magnet thickness between the stator core segments was neglected for convenience, which caused inaccuracy in the flux density calculation. Especially, as the magnet thickness increases, the error also increases in the calculation of back EMF and flux density.

In this study, the precise equations of the air gap magnetic flux density and the back EMF expressed in terms of the actual machine geometries are derived. In order to achieve this purpose, the air gap permanence expression is obtained by deriving the permeance of each side of the stator and rotor and combining both permeances. In particular, to determine the permeance of the stator side in the general case that the widths of the stator slot and the magnet between the stator core segments are different, a superposition theorem is used. Using the proposed air gap permeance and the magnetomotive force (MMF) of the air gap calculated from the equivalent magnetic circuit, the magnetic flux density equation is derived and leads to the back EMF equation. Both equations are used to analyze the characteristics of FSPM motors with geometry variations. From the results, in particular, geometric information of the motor for developing maximum back EMF is obtained. In addition, the validity of the analytical results obtained from the proposed characteristic equations is confirmed by comparing them with the finite element (FE) analysis results.

\section{Description of the Structure of an FSPM Machine}

In the structure of FSPM machines, the rotor without excitation source and the stator core are divided, and magnets are housed between two separated cores, as shown in Figure 1. The maximum values of positive and negative flux linkage are obtained when the stator pole is in position with a rotor pole, according to the flux-switching principle. Besides, the polarity of the coil is altered with the continuous rotation of the salience rotor. In other words, the magnitude and polarity of flux linkage are changed when the rotor pole aligns with the next stator pole. 


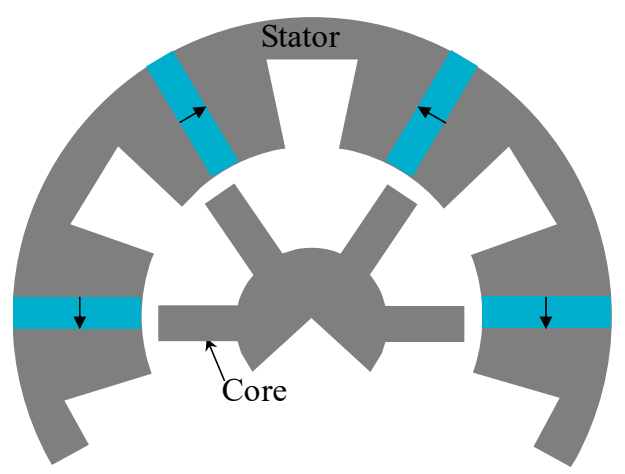

Figure 1. Structure of a flux-switching permanent magnet (PM) machine.

\section{Analytical Approach for a Flux-Switching PM Machine}

The accurate prediction of the magnetic field distribution is a prerequisite to investigate the machine performance at the initial design stage. Therefore, this section will explain the analytical model to calculate the air gap flux density using the accurate permanence and MMF function. In order to develop the analytical calculation model for FSPM machines, the following assumptions were made to simplify the problem:

- The permeabilities of stator and rotor iron are infinite.

- The end effect is ignored.

- The eddy current effects are ignored.

\subsection{Air Gap Permeance}

The accurate calculation of air gap flux density needs an accurate value of permeance. Especially, in flux modulation machines, permeance harmonics play an important role in the production of flux density and back EMF. For this purpose, the permeance of the machine is calculated precisely.

As shown in Figure 1, the FSPM machine has double saliency due to stator slots and rotor teeth. In general, the air gap permeance of a machine with a double-pole shape is obtained by determining the stator's side permeance and the rotor's side permeance and synthesizing the two permeances to obtain the final permeance [14]. Meanwhile, in FSPM, the magnets are buried in the separated stator cores and, since the slot width of one stator core and the width of the magnet are different, it is necessary to calculate the stator side permeance considering this, which was ignored in previous studies.

In this study, the permeance of the stator side is calculated by a method similar to the one previously used for both slotted cores, as follows. The stator was assumed to be divided into two parts: (1) the permeance due to the stators slots without magnets, $P_{s s}$, (2) the permeance due to the stator magnets without slots, $P_{s m}$.

The permeance due to the stator slots and stator magnets is shown in Figure 2, when the reference angle was selected at the center of the stator slot. The permeance of the stator slots and stator magnets are calculated using Equations (1) and (2), respectively.

$$
\begin{gathered}
P_{s s}(\theta)=P_{s s 0}-P_{s s 1} \cos \left(Z_{s} \theta\right) \\
P_{s m}(\theta)=P_{s m 0}+P_{s m 1} \cos \left(2 Z_{m} \theta\right)
\end{gathered}
$$

where $P_{s s 0}$ and $P_{s s 1}$ are the average permeance and fundamental term related to the stator slots, and similarly, $P_{s m 0}$ and $P_{s m 1}$ are the average permeance and fundamental term related to the stator magnets, and these coefficients can be determined on the basis of the geometry of the machine. The overall stator permeance is calculated using an approach similar to that for a double-saliency structure [14], and given in Equation (3): 


$$
\begin{aligned}
P_{S}(\theta) & \approx \frac{g P_{s s}(\theta) P_{s m}(\theta)}{\mu_{0}} \\
& \approx P_{s 0}-P_{s 1} \cos \left(Z_{s} \theta\right)-P_{s 2} \cos \left(2 Z_{s} \theta\right)
\end{aligned}
$$

where $P_{s 0}=g / \mu_{0}\left(P_{s s 0} P_{s m 0}-0.5 P_{s s 1} P_{s m 1}\right), P_{s 1}=g / \mu_{0}\left(P_{s s 1} P_{s m 0}-P_{s s 0} P_{s m 1}\right)$, and $P_{s 2}=g / \mu_{0}\left(P_{s s 1} P_{s m 1} / 2\right)$, respectively.

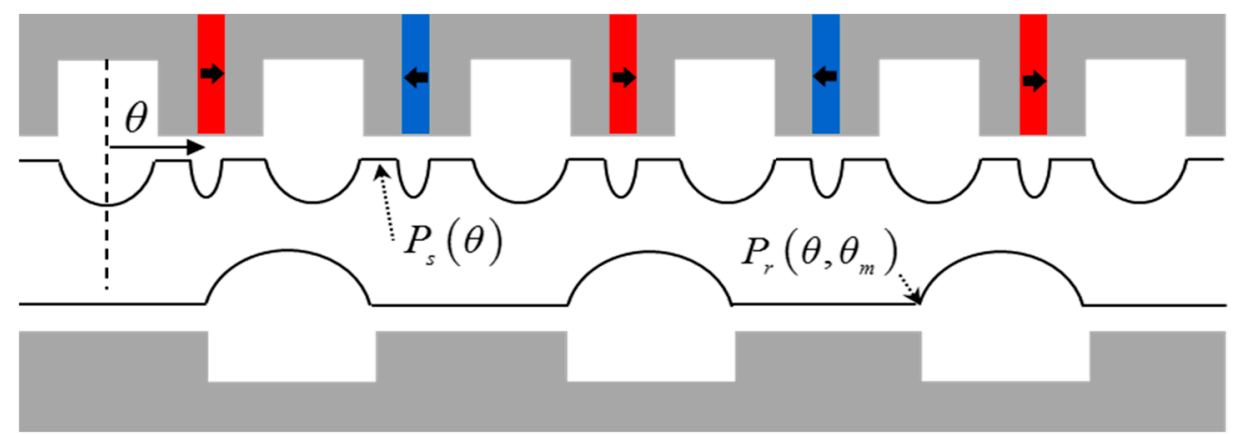

Figure 2. Permeance of a flux-switching PM (FSPM) machine.

In other words, $P_{s 0}, P_{s 1}$, and $P_{s 2}$ are coefficients of total stator permeance that take into account both the slot and the magnet influence. The permeance as seen from the stator looking into the rotor teeth is calculated by Equation (4) and shown in Figure 2. The sign " + " is used because the reference axis is located at the center of the rotor teeth.

$$
P_{r}\left(\theta, \theta_{m}\right)=P_{r 0}+P_{r 1} \cos Z_{r}\left(\theta-\theta_{m}\right)
$$

where $P_{r 0}$ and $P_{r 1}$ are the average and the first harmonic permeance due to the rotor slots, respectively, and their values can be chosen using the machine structure. As aforementioned, the total permeance in the air gap of the double-slotted structure require the contribution of individual side permeances; therefore, $P_{s}(\theta)$ and $P_{r}\left(\theta, \theta_{m}\right)$ were calculated accurately. Thus, the air gap permeance of the FSPM machine can be given as [14]

$$
\begin{aligned}
P_{g}\left(\theta, \theta_{m}\right) & \approx \frac{g P_{s}(\theta) P_{r}\left(\theta, \theta_{m}\right)}{\mu_{0}} \\
& \approx \underbrace{\frac{g}{\mu_{0}} P_{s 0} P_{r 0}}_{G_{0}}-\underbrace{\frac{g}{\mu_{0}} P_{r 0}\left\{P_{s 1} \cos \left(Z_{s} \theta\right)+P_{s 2} \cos \left(2 Z_{s} \theta\right)\right\}}_{G_{1}(\theta)} \\
& +\underbrace{\frac{g}{\mu_{0}} P_{r 1}\left\{P_{s 0} \cos Z_{r}\left(\theta-\theta_{m}\right)-\frac{P_{s 1}}{2}\left\{\cos \left(\left(Z_{s} \mp Z_{r}\right) \theta-Z_{r} \theta_{m}\right)\right\}-\frac{P_{s 2}}{2}\left\{\cos \left(\left(2 Z_{s} \mp Z_{r}\right) \theta-Z_{r} \theta_{m}\right)\right\}\right\}}_{G_{2}\left(\theta, \theta_{m}\right)} \\
& \approx G_{0}-G_{1}(\theta)+G_{2}\left(\theta, \theta_{m}\right)
\end{aligned}
$$

Equation (5) determines the permeance distribution in the air gap. It is seen that the permeance consist of three terms; however, only the third term is a function of the rotor position.

The permeance coefficients in (1)-(4) can be expressed in terms of practical machine geometry [14]. The average and the first harmonic of the permanence function are expressed by Equations (6) and (7):

$$
\begin{gathered}
P_{0}=\frac{\mu_{0}}{g}\left(1-1.6 \beta c_{0}\right) \\
P_{1}=\frac{\mu_{0}}{g} \frac{2 \beta}{\pi}\left(\frac{0.78}{0.78-2 c_{0}^{2}}\right) \sin \left(1.6 \pi c_{0}\right) \\
\beta=0.5-\frac{1}{\sqrt{4+\left(\frac{o}{g}\right)^{2}}}
\end{gathered}
$$


As mentioned above, $P_{s s 0}, P_{s s 1}, P_{s m 0}, P_{s m 1}, P_{r 0}$, and $P_{r 1}$ in (1), (2), and (4) are the average and the first harmonic function of stator slots, stator magnets, and rotor slots geometries, and the magnitude of these coefficients can be found using the respective geometries in Equations (6), (7), and (8). The ratio of slot opening to slot pitch $c_{0}$ is described in Figure 3. The coefficient $\beta$ is the nonlinear function of slot opening to air gap length, whose maximum value is less than 0.5 , as depicted in Figure 4 . To get the high back EMF, it is essential to focus on $\beta$ because the value of $P_{1}$ is proportional to $\beta$ when $c_{0}$ is constant. In other words, the highest power density can be achieved when the value of $\beta$ is close to 0.5 .

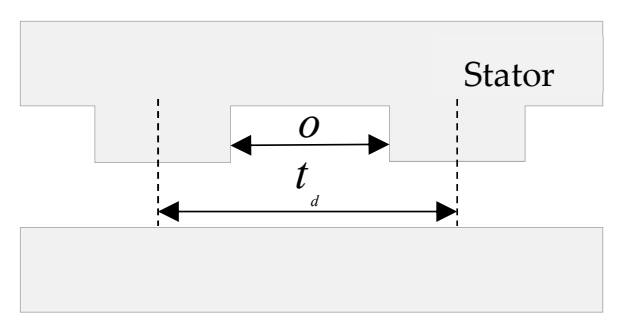

Figure 3. Slot opening parameters.

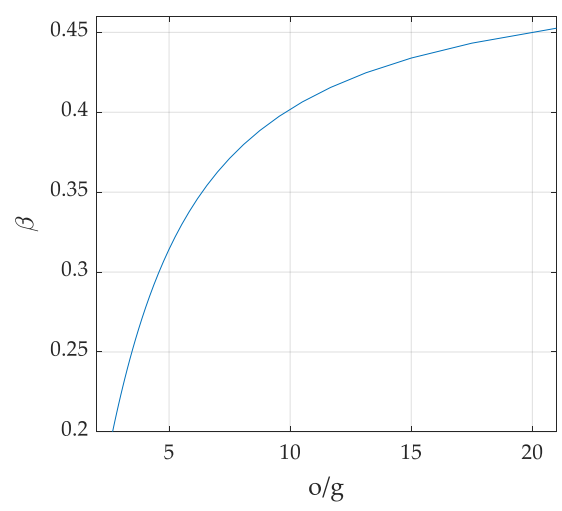

Figure 4. Parameter $\beta$ versus o/g.

\subsection{Magnetomotive Force (MMF)}

To calculate the air gap flux density, it is necessary to obtain the MMF applied to the air gap by PM. However, in the structure of FSPM, the stator core is divided, and the magnets are buried between the stator cores; therefore, the potential of each core piece should be obtained first.

To these end, a magnetic circuit with the lumped parameters considering the complex geometries due to the stator and the PM was established, as shown in Figures 5 and 6 . The airgap lumped reluctance $R_{g}$ facing each stator core was obtained using the air gap permeance function of stator and rotor slots according to Equation (9).

$$
R_{g . k}=\frac{1}{r_{g} l_{s t k} \int_{\frac{2 \pi}{Z_{s}}(k-1)}^{\frac{2 \pi}{Z_{s}} k} P_{g}\left(\theta, \theta_{m}\right) d \theta}
$$

The integral term of the denominator is summarized and given in Equation (10):

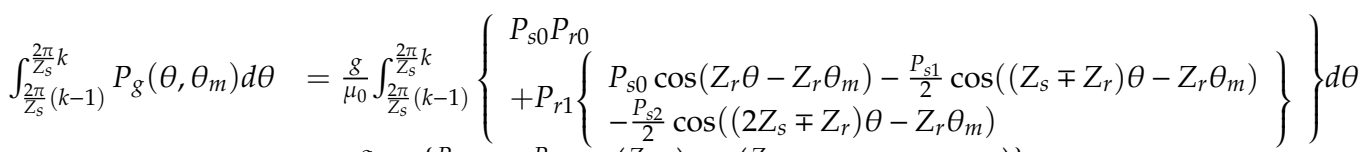

$$
\begin{aligned}
& \approx 2 \frac{g}{\mu_{0}} P_{s 0}\left\{\frac{P_{r 0}}{Z_{s}} \pi+\frac{P_{r 1}}{Z_{r}} \sin \left(\frac{Z_{r}}{Z_{s}} \pi\right) \cos \left(\frac{Z_{r}}{Z_{s}}(2 k-1) \pi-Z_{r} \theta_{m}\right)\right\}
\end{aligned}
$$




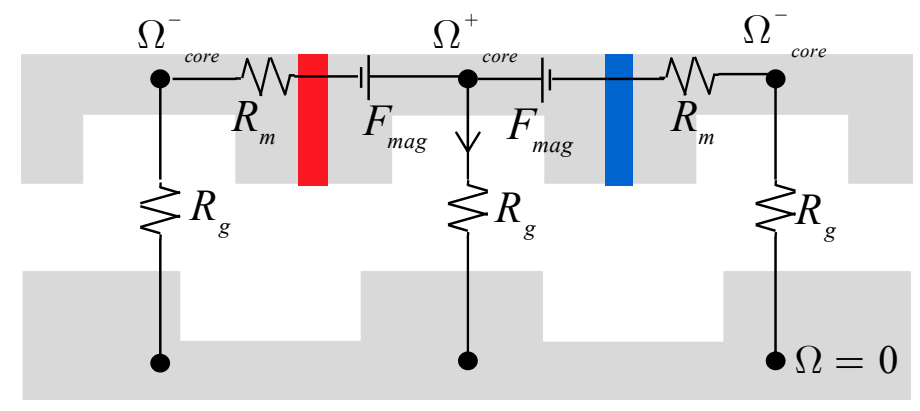

Figure 5. Conception of the magnetic circuit based on geometry.

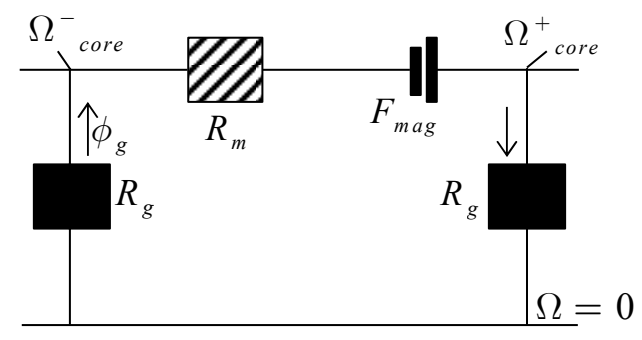

Figure 6. Magnetic equivalent circuit of the FSPM machine.

Equation (10) shows that the magnetic resistance varies with the position of the rotor, so the potential of the iron core also oscillates with the position of the rotor. However, $P_{0}$ is considerably larger than $P_{1}$, and there is no big difference between $Z_{r}$ and $Z_{s}$ in the FSPM machine. Therefore, the size of the vibration term is very small compared to the size of the first term in parentheses. Thus, it can be assumed that the values of the magnetic resistance are the same, according to the following Equation (11):

$$
R_{g}=\frac{Z_{s} \mu_{0}}{2 \pi r_{g} l_{s t k} g P_{s 0} P_{r 0}}
$$

Considering the same assumption, the magnetic circuit was solved, and the magnetic potential of each stator core piece was analytically calculated according to Equation (12):

$$
\Omega_{\text {core }}^{+}\left(=-\Omega_{\text {core }}^{-}\right)=R_{g} \varphi=\frac{F_{\text {mag }}}{\left(\frac{R_{m}}{2 R_{g}}+2\right)}
$$

where $F_{m a g}=\left(g_{m} / \mu_{m}\right) B_{r}$ and $R_{m}=\left(g_{m} / \mu_{m} A_{m}\right)$ are MMF and reluctance developed by the magnet. Now, the potential of the stator surface, $\Omega^{+}$core and $\Omega^{-}$core, are obtained using Equations (11) and (12), and thus the MMF distribution in the air gap can be expressed by Equation (13):

$$
\begin{aligned}
F_{g}(\theta) & =F_{g m} \sum_{m=1,3} \frac{(-1)^{\frac{m-1}{2}}}{m} \cos m\left(Z_{m} \theta\right) \\
& \approx F_{g m}\left(\cos Z_{m} \theta-\frac{1}{3} \cos 3 Z_{m} \theta\right)
\end{aligned}
$$

where $F_{g m}=(4 / \pi) \Omega^{+}$core, and the harmonic whose order is greater than 3 is ignored because of small magnitude.

\subsection{Air Gap Flux Density}

The air gap magnetic flux density due to the stator PMs can be calculated as the product of the magnet MMF, $F_{g}(\theta)$, and the air gap permeance function, $P_{g}\left(\theta, \theta_{m}\right)$, according to Equation (14): 


$$
\begin{aligned}
B_{g}\left(\theta, \theta_{m}\right) & =F_{g}(\theta) P_{g}\left(\theta, \theta_{m}\right) \\
& =F_{g}(\theta)\left\{G_{0}-G_{1}(\theta)+G_{2}\left(\theta, \theta_{m}\right)\right\} \\
& =\underbrace{G_{0} F_{g}(\theta)-G_{1}(\theta) F_{g}(\theta)}_{B_{\text {stat }}(\theta)}+\underbrace{G_{2}\left(\theta, \theta_{m}\right) F_{g}(\theta)}_{B_{m o v}\left(\theta, \theta_{m}\right)}
\end{aligned}
$$

which shows that the air gap flux density of the FSPM machine comprises three terms; since the first two terms, $G_{0} F_{\mathrm{g}}(\theta)$ and $G_{1}(\theta) F_{\mathrm{g}}(\theta)$, do not depend on the rotor position $\theta_{m}$, they are denoted as $B_{\text {stat }}$. Using $Z_{s}=2 Z_{m}, B_{\text {stat }}$ can be easily indicated as

$$
B_{\text {stat }}(\theta) \approx \frac{g}{\mu_{0}} F_{g m} P_{r 0}\left\{\begin{array}{l}
\left(P_{s 0}-\frac{P_{s 1}}{3}+\frac{P_{s 2}}{6}\right) \cos Z_{m} \theta-\frac{1}{3}\left(P_{s 0}+\frac{3}{2} P_{s 1}+\frac{3}{2} P_{s 2}\right) \cos 3 Z_{m} \theta \\
+\left(\frac{P_{s 1}}{6}-\frac{P_{s 2}}{2}\right) \cos 5 Z_{m} \theta+\frac{P_{s 2}}{6} \cos 7 Z_{m} \theta
\end{array}\right\}
$$

The third term $G_{2}\left(\theta, \theta_{m}\right) F_{\mathrm{g}}(\theta)$ of Equation (14), denoted as $B_{m o v}$, is dependent on the rotor position $\theta_{m}$ and summarized in (16):

$$
B_{m o v}\left(\theta, \theta_{m}\right) \approx \frac{g F_{g m} P_{r 1}}{\mu_{0} 2}\left\{\begin{array}{l}
\Lambda_{S 1} \cos \left(\left(Z_{m}-Z_{r}\right) \theta-Z_{r} \theta_{m}\right)+\Lambda_{S 2} \cos \left(\left(Z_{m}-Z_{r}\right) \theta+Z_{r} \theta_{m}\right) \\
+\Lambda_{S 3} \cos \left(\left(Z_{m}+Z_{r}\right) \theta-Z_{r} \theta_{m}\right)+\Lambda_{S 4} \cos \left(\left(Z_{m}+Z_{r}\right) \theta+Z_{r} \theta_{m}\right) \\
-\Lambda_{S 5} \cos \left(\left(3 Z_{m}-Z_{r}\right) \theta-Z_{r} \theta_{m}\right)-\Lambda_{S 6} \cos \left(\left(3 Z_{m}-Z_{r}\right) \theta+Z_{r} \theta_{m}\right) \\
-\Lambda_{S 7} \cos \left(\left(3 Z_{m}+Z_{r}\right) \theta-Z_{r} \theta_{m}\right)
\end{array}\right\}
$$

where $\Lambda_{\mathrm{s} 1}-\Lambda_{\mathrm{s} 7}$ are the coefficients that represent the input of total stator side permanence in $B_{\text {mov }}$, and the magnitude of each coefficient is indicated in Table 1.

Table 1. Total permeance coefficients of the stator side.

\begin{tabular}{cccc}
\hline Coefficient & Magnitude & Number of Pole Pairs & Speed \\
\hline$\Lambda_{\mathrm{s} 1}, \Lambda_{\mathrm{s} 2}$ & $\left(-\frac{1}{2} P_{s 1}+\frac{1}{6} P_{s 2}\right),\left(P_{s 0}+\frac{1}{6} P_{s 1}\right)$ & $\left|Z_{m}-Z_{r}\right|$ & $\frac{Z_{r}}{\left|Z_{m}-Z_{r}\right|} \omega_{m}$ \\
$\Lambda_{\mathrm{s} 3}, \Lambda_{\mathrm{s} 4}$ & $\left(P_{\mathrm{s} 0}-\frac{1}{2} P_{s 1}+\frac{1}{6} P_{s 2}\right),\left(\frac{1}{6} P_{s 1}\right)$ & $\left|Z_{m}+Z_{r}\right|$ & $\frac{Z_{r}}{\left|Z_{m}+Z_{r}\right|} \omega_{m}$ \\
$\Lambda_{\mathrm{s} 5}, \Lambda_{\mathrm{s} 6}$ & $\left(\frac{1}{2} P_{s 1}+\frac{1}{2} P_{s 2}\right),\left(\frac{1}{3} P_{s 0}\right)$ & $\left|3 Z_{m}-Z_{r}\right|$ & $\frac{\left|3 Z_{m}-Z_{r}\right|}{Z_{m}} \omega_{m}$ \\
$\Lambda_{\mathrm{s} 7}$ & $\left(\frac{1}{3} P_{s 0}+\frac{1}{2} P_{s 1}+\frac{1}{2} P_{s 2}\right)$ & $\left|3 Z_{m}+Z_{r}\right|$ & $\frac{Z_{r}}{\left|3 Z_{m}+Z_{r}\right|} \omega_{m}$ \\
\hline
\end{tabular}

From Table 1, it can be seen that $\Lambda_{s 2}$ has the largest magnitude and fastest speed among the coefficients, which means this term will provide the highest contribution to the generation of back EMF. Therefore, to achieve the best performance, it is necessary to install a winding considering this flux component. The back EMF must be obtained from the magnetic flux distribution with the pole number of $\left|Z_{m}-Z_{r}\right|$, and the most common pole/slot combination for a three-phase slot-concentrated machine is $2: 3$ or $4: 3$. By using the condition $\left|Z_{m}-Z_{r}\right| / Z_{s}=4: 3$ or $2: 3$ and $Z_{s}=2 Z_{m}$, the following results are obtained.

From Table 2, it is seen that the $-2: 3$ pole/slot combination has the fastest magnetic field rotation, which is advantageous for increasing the back EMF. Based on this, the analysis model with 12 slots and 10 rotor poles was chosen for investigation in this study, which is a multiple combination corresponding to $-2: 3$ in the above table. For the slot-concentrated winding configuration, assuming for convenience that three slots make up one winding pole pair $p$, that is, $Z_{s}=3 p$, the selected model has four winding pole pairs. By using this model, the air gap flux density waves of the FSPM machine was obtained analytically and is depicted in Figure 7. 
Table 2. Pole/slot combination selection.

\begin{tabular}{cccc}
\hline $\begin{array}{c}\text { Pole/Slot Combination } \\
\left(Z_{s}-\mathbf{2} Z_{r} / Z_{s}\right)\end{array}$ & $Z_{s}$ & $\begin{array}{c}\text { Number of Pole Pairs, } \\
\left|Z_{m}-Z_{r}\right|\end{array}$ & Speed, $\frac{Z_{r}}{\left|Z_{m}-Z_{r}\right|} \omega_{m}$ \\
\hline $4: 3$ & $-6 Z_{r}(<0$, not feasible $)$ & - & - \\
\hline$-4: 3$ & $6 / 7 Z_{r}$ & $4 / 7 Z_{r}$ & $7 / 4 \omega_{m}$ \\
\hline $2: 3$ & $6 Z_{r}$ & $2 Z_{r}$ & $1 / 2 \omega_{m}$ \\
\hline$-2: 3$ & $6 / 5 Z_{r}$ & $2 / 5 Z_{r}$ & $5 / 2 \omega_{m}$ \\
\hline
\end{tabular}

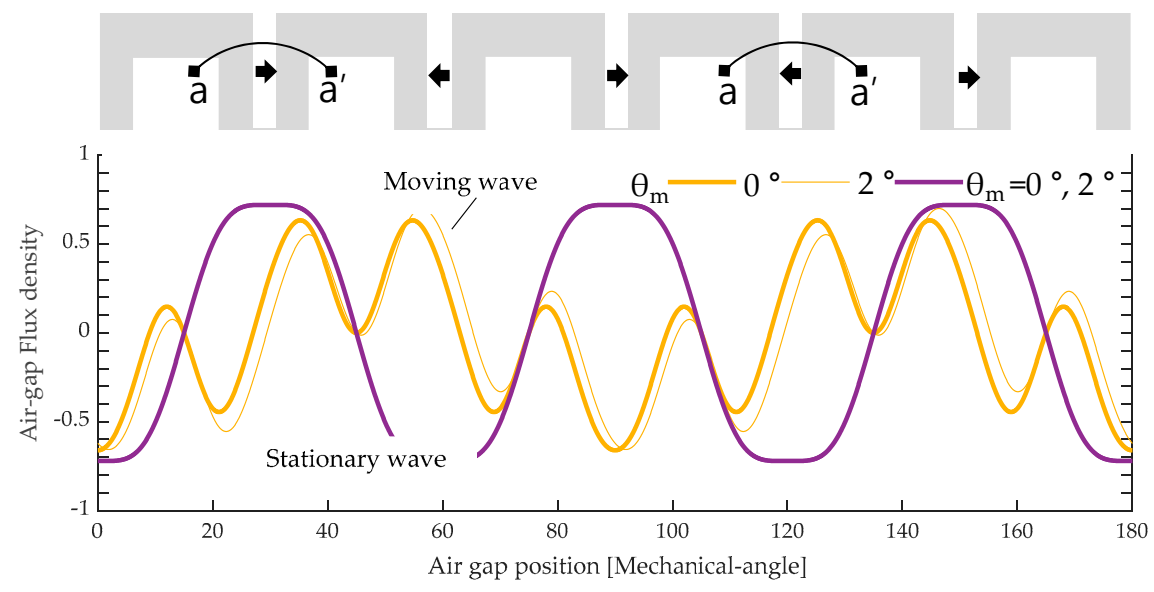

Figure 7. The stationary and moving flux waveforms of the air gap of the FSPM machine.

As seen in Equations (15) and (16), the terms $B_{\text {stat }}$ is the stationary flux density, and $B_{\text {mov }}$ is the moving flux density of the FSPM machine. Thus, the moving wave $B_{\text {mov }}$ alone contributes to the production of back EMF. To understand the concept, both waves are depicted in Figure 7 for each instance, $\theta_{m}=0^{\circ}$ and $2^{\circ}$, and it is clearly shown that only the moving flux wave $B_{\text {mov }}$ is changing position with the rotor movement. Therefore, for an FSPM machine, one must focus on the $B_{\text {mov }}$ term in Equation(16), and the magnitudes of each working harmonic component of the air gap flux density depend on $\left(Z_{m}-Z_{r}\right),\left(Z_{m}+Z_{r}\right)$, $\left(3 Z_{m}-Z_{r}\right)$, and $\left(3 Z_{m}+Z_{r}\right)$.

\section{Calculation of Back EMF}

The back EMF can be obtained from the air-gap flux density distribution with the information of the winding distribution. As aforementioned, the air gap flux density of an FSPM machine consists of a stationary and a moving flux wave, and only the moving flux wave $B_{\text {mov }}$ contributes to the back EMF, so the back EMF of an FSPM machine can be obtained from Equation (16):

$$
\begin{aligned}
e_{b} & =\frac{D_{g}}{2} p N_{p} l_{s t k} \omega_{m} \frac{d}{d t} \int_{0}^{\frac{2 \pi}{Z_{s}}} B_{m o v}\left(\theta, \theta_{m}\right) d \theta \\
& =\frac{D_{g}}{2} p N_{p} l_{s t k} \omega_{m} \frac{d}{d t} \int_{0}^{\frac{2 \pi}{Z_{s}}} \frac{g F_{g m} P_{r 1}}{\mu_{0} 2}\left\{\begin{array}{l}
\Lambda_{S 1} \cos \left(\left(Z_{m}-Z_{r}\right) \theta-Z_{r} \theta_{m}\right)+\Lambda_{S 2} \cos \left(\left(Z_{m}-Z_{r}\right) \theta+Z_{r} \theta_{m}\right) \\
+\Lambda_{S 3} \cos \left(\left(Z_{m}+Z_{r}\right) \theta-Z_{r} \theta_{m}\right)+\Lambda_{S 4} \cos \left(\left(Z_{m}+Z_{r}\right) \theta+Z_{r} \theta_{m}\right) \\
-\Lambda_{S 5} \cos \left(\left(3 Z_{m}-Z_{r}\right) \theta-Z_{r} \theta_{m}\right)-\Lambda_{S 6} \cos \left(\left(3 Z_{m}-Z_{r}\right) \theta+Z_{r} \theta_{m}\right) \\
-\Lambda_{S 7} \cos \left(\left(3 Z_{m}+Z_{r}\right) \theta-Z_{r} \theta_{m}\right)
\end{array}\right\} d \theta
\end{aligned}
$$

Using $Z_{m}=Z_{s} / 2$ and $Z_{s}=3 p$, the terms $Z_{m}$ and $Z_{r}$ of Equation (17) can be replaced with $3 / 2 p$ and $(5 / 2) p$, respectively, and then one obtains

$$
e_{b}=p N_{p} l_{s t k} \omega_{m} \frac{D_{g}}{2} \frac{g F_{g m} P_{r 1}}{\mu_{0} 2} \frac{d}{d t} \int_{0}^{\frac{2 \pi}{Z_{S}}}\left\{\begin{array}{l}
\Lambda_{S 1} \cos \left(p \theta+Z_{r} \theta_{m}\right)+\Lambda_{S 2} \cos \left(p \theta-Z_{r} \theta_{m}\right) \\
+\Lambda_{S 3} \cos \left(4 p \theta-Z_{r} \theta_{m}\right)+\Lambda_{S 4} \cos \left(4 p \theta+Z_{r} \theta_{m}\right) \\
-\Lambda_{S 5} \cos \left(2 p \theta-Z_{r} \theta_{m}\right)-\Lambda_{S 6} \cos \left(2 p \theta+Z_{r} \theta_{m}\right) \\
-\Lambda_{S 7} \cos \left(7 p \theta-Z_{r} \theta_{m}\right)
\end{array}\right\} d \theta
$$


Hereafter, the terms $\Lambda_{s 4}$ and $\Lambda_{s 7}$ are ignored because of their very low contribution to back EMF. Finally, by solving Equation (18), the back EMF of an FSPM machine is summarized as

$$
\begin{aligned}
e_{b} & =k_{\text {add }}\left\{\Lambda_{S 2} \sin \left(\frac{\pi}{3}-Z_{r} \theta_{m}\right)-\Lambda_{S 1} \sin \left(\frac{\pi}{3}+Z_{r} \theta_{m}\right)\right\} \\
& +\frac{k_{\text {add }}}{2}\left\{\Lambda_{S 6} \sin \left(\frac{2 \pi}{3}+Z_{r} \theta_{m}\right)-\Lambda_{S 5} \sin \left(\frac{2 \pi}{3}-Z_{r} \theta_{m}\right)\right\} \\
& -\frac{k_{\text {add }}}{4}\left\{\Lambda_{S 3} \sin \left(\frac{4 \pi}{3}-Z_{r} \theta_{m}\right)\right\}
\end{aligned}
$$

This equation shows that the back EMF is composed of three terms, with the first two terms contributing the most, and each of them is composed of two waves that move in opposite directions. Herein, $K_{a d d}$ is the magnitude of back EMF excluding the stator side permanence effect, which is expressed by

$$
k_{\text {add }}=\frac{\sqrt{3} g F_{g m} P_{r 1}}{4 \mu_{0}} N_{p} \omega_{m} l_{s t k} Z_{r} D_{g}
$$

Equation (20) shows that the MMF and the first harmonic of rotor permanence play a vital role in the production of back EMF, and the average permanence of the rotor side does not contribute to the back EMF. Equations (7) and (12) imply that the magnet thickness $g_{m}$ and the ratio of the rotor slot opening to the slot pitch $c_{r o}$ have a significant influence on back EMF production. The back EMF performance with different $g_{m}$ and $c_{r o}$ will be discussed in Section 6.

\section{Air Gap Flux Density Verification through FE Simulation}

To prove the validity of the derived analytical expressions, first, a prototype flux-switching structure was chosen, whose specifications are shown in detail in Table 3. The geometry of the machine is depicted in Figure 8.

Table 3. Specifications for finite element (FE) analysis and performance values estimated from the corresponding equations.

\begin{tabular}{cccc}
\hline Parameters & Value & Parameters & Value \\
\hline Stator inner diameter & $406[\mathrm{~mm}]$ & Rotor outer diameters & $402[\mathrm{~mm}]$ \\
Stator Slots & 12 & Magnet type & NdFeB \\
Turns per phase & $200[$ Turns] & Air-gap length & $2[\mathrm{~mm}]$ \\
Rated speed & $1200 \mathrm{RPM}$ & Stack length & $50[\mathrm{~mm}]$ \\
Rotor pole & 10 & & \\
\hline
\end{tabular}

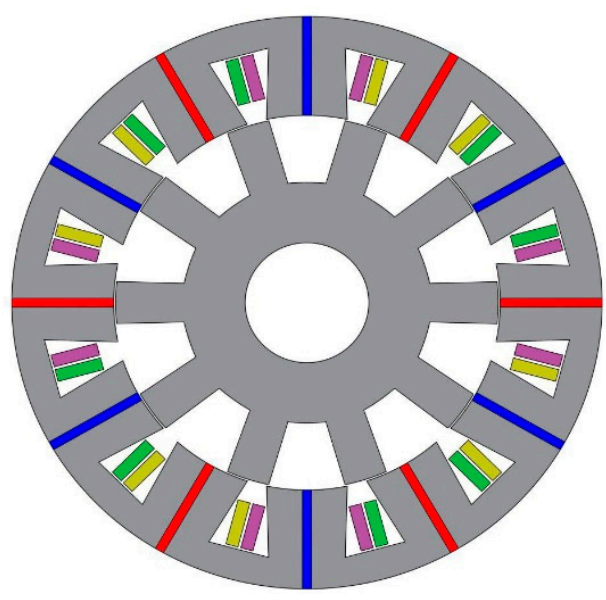

Figure 8. Prototype of a flux-switching PM machine. 
Equations (14)-(16) show the analytical expression of the air gap flux density, considering the fundamental component and third harmonic of MMF of the magnet and the first harmonic of air gap permeance, respectively. To verify these, finite-element computations were performed with different $g_{m}$ and $c_{r 0}$ structures, and the results were compared with those of the analytical calculations in Figures $9 \mathrm{a}$ and 10a. The obtained results showed good agreement between the analytical and the FE method.

The harmonics of the waveforms obtained from the proposed method and the FE method were also compared in Figures $9 \mathrm{~b}$ and $10 \mathrm{~b}$. Moreover, the magnitude of harmonics and error between them is shown in Table 4, which illustrates that the magnitudes of the 4th, 6th, and 16th harmonic are closer to those determined by the FE method, however, the deviation increases in the 8th and 18th harmonic order. The reason is because only the first and third harmonic of MMF and the first harmonic of permeance were considered in the air gap flux density expression, while the FE analysis considered all harmonics of MMF and air gap permeance in the form of Fourier series to calculate the air gap flux density. However, it should be noted that the main contribution to the back EMF was due to the $\left(Z_{m}-Z_{r}\right)$ harmonic order, which was the 4 th of the selected combination. It can be seen from Table 4 that the error in the 4 th harmonic was only $3 \%$. Therefore, the deviation in other harmonics did not influence the result of back EMF.

In addition, the no-load flux distribution and flux density of the flux-switching PM structure having $g_{m}=10 \mathrm{~mm}$ and $c_{r 0}=0.6$ are illustrated in Figure 11 .

Table 4. Magnitude of harmonics and error determined by the analytical and FE methods.

\begin{tabular}{cccc}
\hline Harmonic Order & Analytical & FEM & Error \\
\hline 4th & 0.335 & 0.347 & $3 \%$ \\
6th & 1 & 1 & $0 \%$ \\
8th & 0.162 & 0.295 & $45 \%$ \\
16th & 0.329 & 0.381 & $15 \%$ \\
18th & 0.489 & 0.641 & $24 \%$ \\
\hline
\end{tabular}

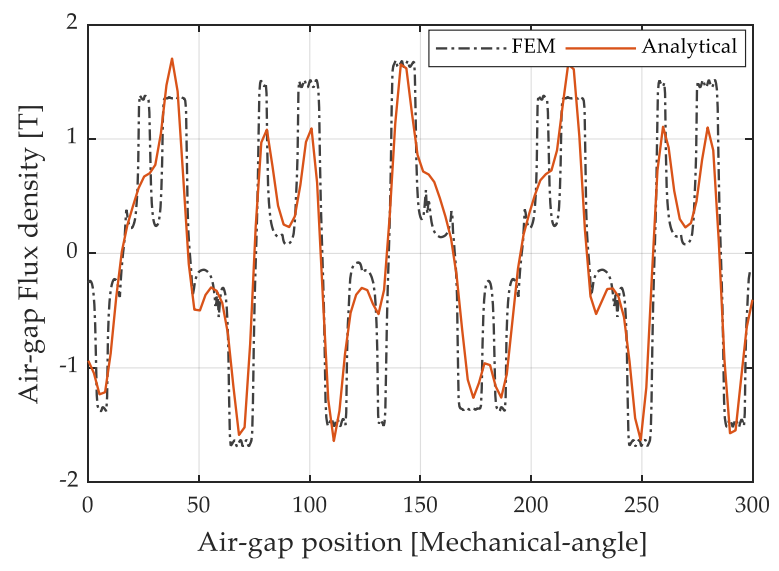

(a)

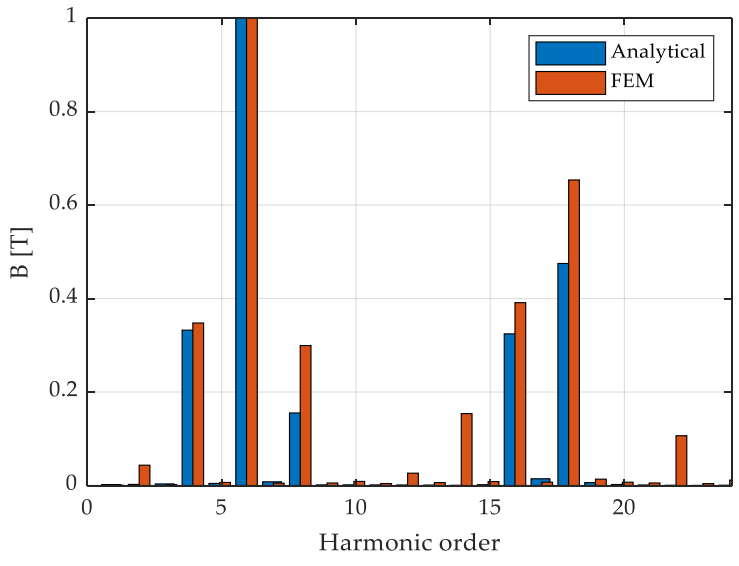

(b)

Figure 9. Analytical and FE results of the air gap flux density, with $g_{m}=10 \mathrm{~mm}$ and $c_{r 0}=0.4$. (a) Waveforms (b) Magnitude of each harmonic. 


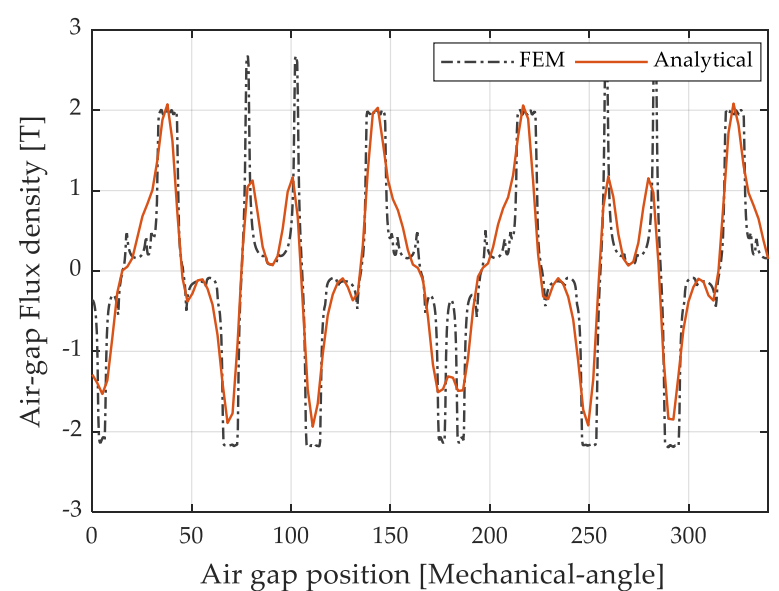

(a)

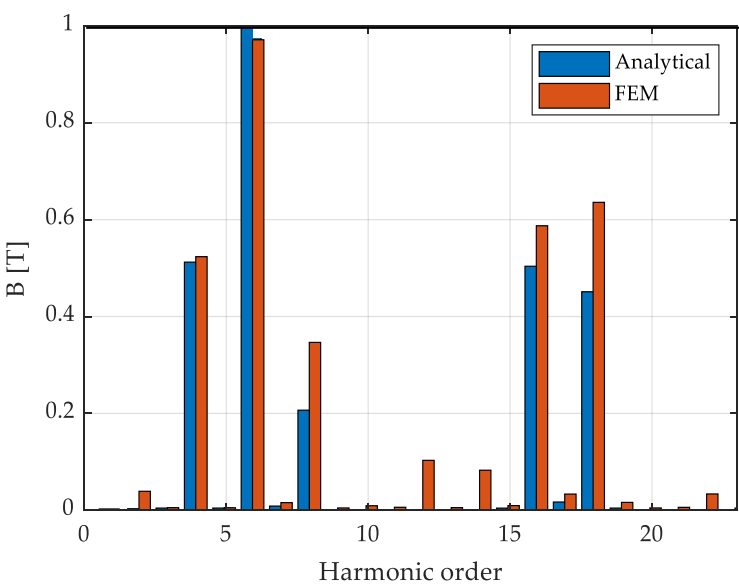

(b)

Figure 10. Analytical and FE results of the air gap flux density, with $g_{m}=15 \mathrm{~mm}$ and $c_{r 0}=0.6$. (a) Waveforms (b) Magnitude of each harmonic.
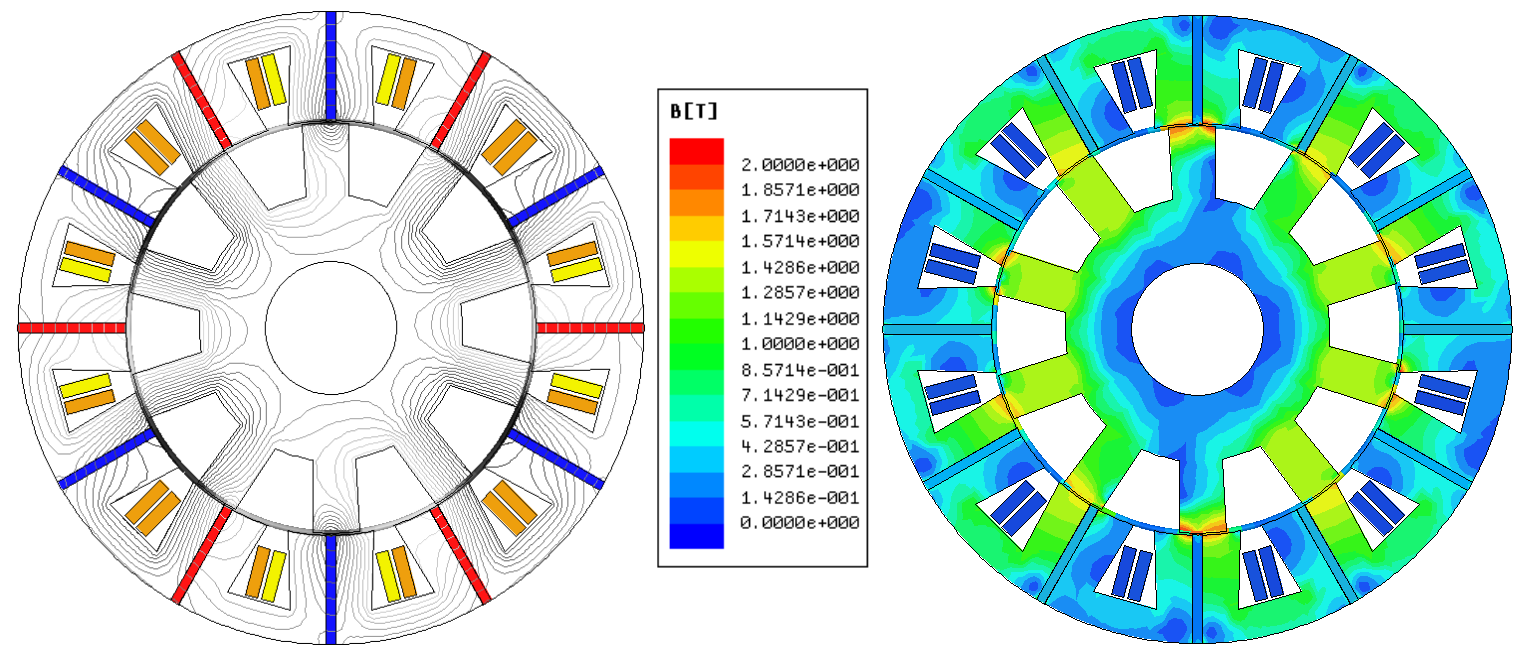

Figure 11. Flux distribution and flux density of the FE model with no-load.

\section{Dependency of Performance Characteristics on Machine Geometries}

As aforementioned, the geometrical parameters $g_{m}$ and $c_{r o}$ have a significant effect on machine performance, so using the Table 3 specifications in Equation (19), a 3D graph was obtained in an analytical way, with different $g_{m}$ and $c_{r o}$, as depicted in Figure 12.

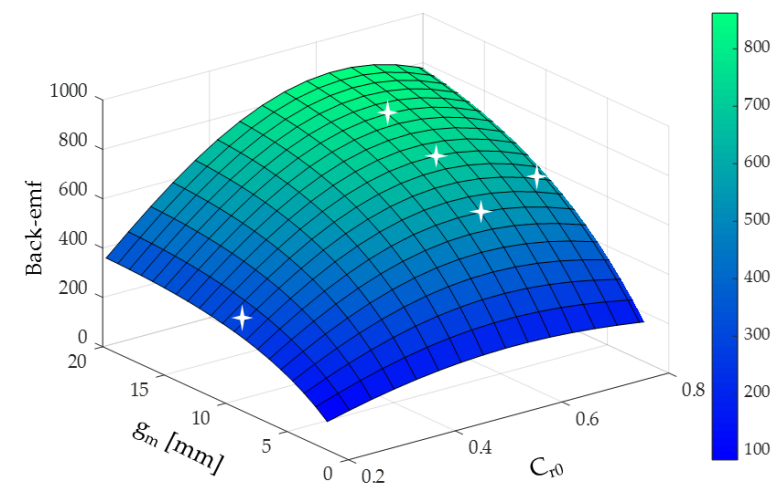

Figure 12. Variation of back electromotive force (EMF) with $g_{m}$ and $c_{r 0}$. 
Figure 12 clearly illustrates the back EMF characteristics with different $g_{m}$ and $c_{r 0}$. The back EMF increased with $g_{m}$, which is similar to what observed for conventional PM machine. Besides, the back EMF maximized around a ratio of rotor slot opening to slot pitch $\left(c_{r 0}\right)$ of 0.6. Finally, in order to investigate the accuracy and effectiveness of Equation (19), some values were chosen for FE analysis, as indicated by the white mark in Figure 12.

Figure 13a compares the finite-element and analytically calculated phase back-EMF waveforms at different values of $c_{r 0}$ and fixed $g_{m}=10 \mathrm{~mm}$. Similarly, the comparison of back EMF waveforms obtained from the analytical and FE methods at different values of $g_{m}$ and fixed $c_{r 0}=0.6 \mathrm{~mm}$ are depicted in Figure 13b. Figure 13 results show an excellent correspondence between the analytical and the FE methods. It is clearly seen that $c_{r 0}$ has a significant impact on back EMF production and maximizes near $c_{r 0}=0.6$; also, a general trend of back EMF rising with $g_{m}$ is shown, as predicted in Figure 12.

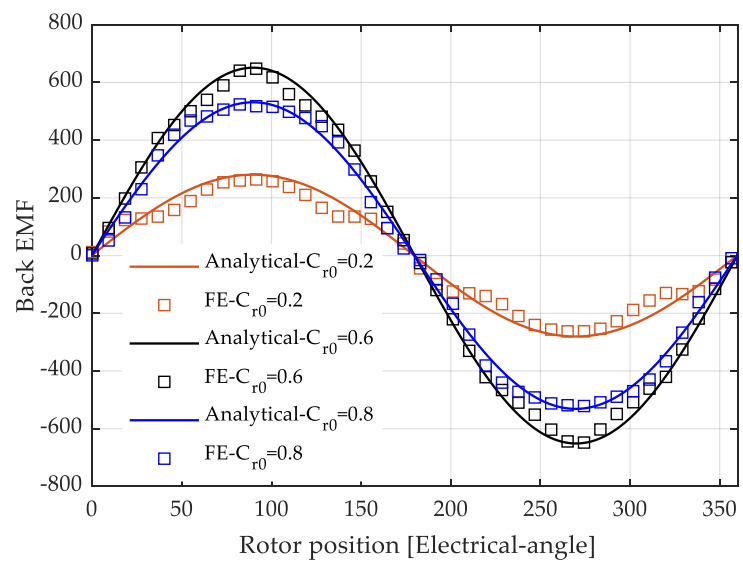

(a)

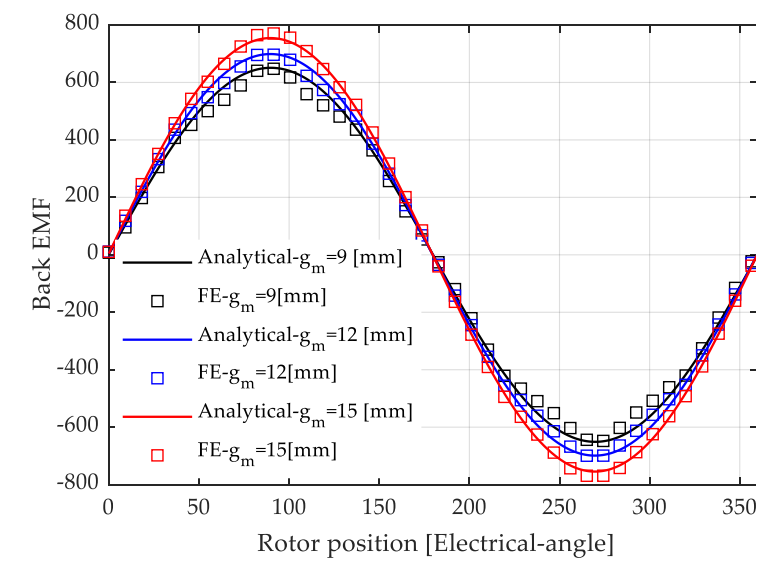

(b)

Figure 13. Analytical and FE results of back EMF, with different $g_{m}$ and $c_{r 0}$. (a) When $g_{m}=10 \mathrm{~mm}$ and $c_{r 0}$ varies (b) when $c_{r 0}=0.6 \mathrm{~mm}$ and $g_{m}$ varies.

In addition, for an accurate analytical model, it is necessary to include the permeance due to the stator-side magnet, as discussed in Section 3.1. Figure 14 compares the FE and analytical results with and without considering the stator-side magnets permeance in the back EMF equation. The figure shows that, without considering the permeance due to the stator-side magnet, the error between analytical and finite element simulations increased by $10 \%$.

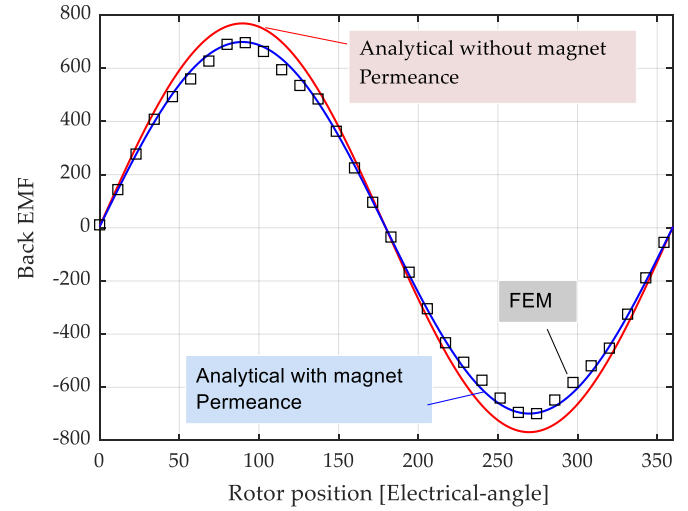

(a)

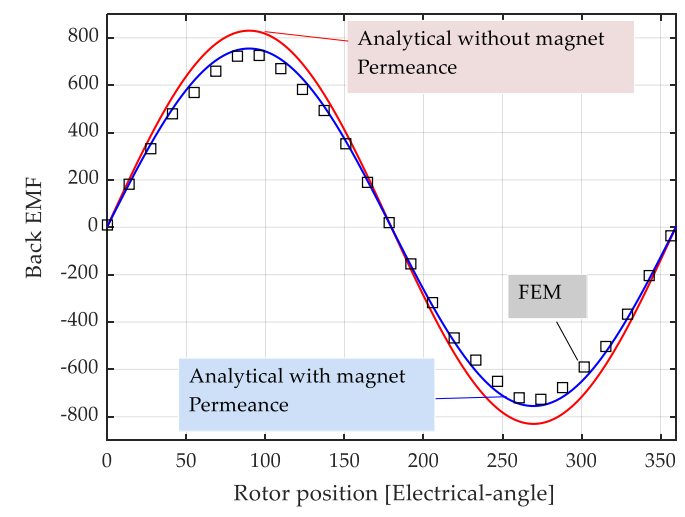

(b)

Figure 14. Back EMF calculation to confirm the effect of permeance due to stator-side magnet gap. (a) When $g_{m}=12 \mathrm{~mm}$ (b) when $g_{m}=15 \mathrm{~mm}$. 


\section{Conclusions}

In this study, the analytical expressions for air gap flux density and back EMF in relation to the machine geometry of an FSPM motor are presented. Using these equations, the nature of an FSPM machine was analytically examined. From the proposed expressions, it was found that the air gap flux density consists of two waves, a stationary wave and a moving wave. Only the moving wave contributes to back EMF and, owing to this, the FSPM machine is classified into the flux-modulation machine family. In contrast, conventional PM machines develop the torque by average permeance and MMF, while the first harmonic of permeance has no contribution because of its small magnitude and slow speed, which is different from the FSPM machine. The derived back-EMF equation, representing the machine geometry parameters, can be used for optimization to get the maximum achievable back EMF.

The analytical calculation results were compared with those of the finite-element simulation, and the accuracy and the effectiveness of the derived expressions were proven. These analytical expressions can be used as a convenient tool at the initial design stage of an FSPM machine. Besides, the influence of rotor slot opening to slot pitch ratio on the electromagnetic performance of the FSPM machines was inspected for the first time. The relation in Equation (16), $Z_{m}-Z_{r}=-p$, shows there is more than one combination that can be applied to achieve the moving flux and back EMF; therefore, this relationship can help to find suitable combinations for FSPM machines in the future.

Author Contributions: Conceptualization, B.K.; methodology, B.K.; software, M.A.; validation, M.A.; formal analysis, M.A.; investigation, M.A.; resources, M.A.; data curation, M.A.; writing-original draft preparation, M.A.; writing-review and editing, B.K.; visualization, M.A.; supervision, B.K.; project administration, B.K.; funding acquisition, B.K.

Funding: This work was supported in part by the Korea Electric Power Corporation under Grant R18XA04 and in part by the National Research Foundation of Korea funded by the Ministry of Education through the Basic Science Research Program under Grant NRF-2017R1A2B4009919.

Conflicts of Interest: The authors declare no conflict of interest.

\section{Nomenclature}

$Z_{S} \quad$ Number of stator slots

$Z_{m} \quad$ Number of magnet pole pairs

$\theta \quad$ Angular position in air gap

$g \quad$ Air gap length

$\mu_{0} \quad$ Permeability of vacuum

$Z_{r} \quad$ Number of rotor pole

$\theta_{m} \quad$ Rotor position

$o \quad$ Slot opening

$t_{d} \quad$ Slot pitch

$c_{0} \quad$ Ratio of slot opening to a slot pitch

$R_{g} \quad$ Airgap lumped reluctance

$r_{g} \quad$ Air gap radius

$l_{\text {stk }} \quad$ Stack length

$B_{r} \quad$ Residual flux density

$g_{m} \quad$ Magnet thickness

$A_{m} \quad$ Area of magnet

$\mu_{m} \quad$ Permeability of magnet

$p \quad$ Winding pole pair

$N_{p} \quad$ Number of turns per poles

$\omega_{m} \quad$ Mechanical speed of rotor

$D_{g} \quad$ Air gap diameter 


\section{References}

1. Rauch, S.E.; Johnsan, L.J. Design Principles of flux-switch Alternators. AIEE Trans. 1955, 74, 1261-1268.

2. Hoang, E.; Ben-Ahmed, A.H.; Lucidarme, J. Switching flux permanent magnet polyphased machines. Eur. Conf. Power Electron. Appl. 1997, 3, 903-908.

3. Chen, J.T.; Zhu, Z.Q. Winding configurations and optimal stator and rotor pole combination of flux-switching PM brushless AC machines. IEEE Trans. Energy Convers. 2010, 25, 293-302. [CrossRef]

4. Deodhar, R.P.; Pride, A.; Iwasaki, S.; Bremner, J.J. Performance improvement in flux-switching PM machines using flux diverters. IEEE Trans. Ind. Appl. 2014, 50, 973-978. [CrossRef]

5. Zhu, Z.Q.; Chen, J.T. Advanced Flux-Switching Permanent Magnet Brushless Machines. IEEE Trans. Magn. 2010, 46, 1447-1453. [CrossRef]

6. Thomas, A.S.; Zhu, Z.Q.; Wu, L.J. Novel Modular-Rotor Switched-Flux Permanent Magnet Machines. IEEE Trans. Ind. Appl. 2012, 48, 2249-2258. [CrossRef]

7. Zulu, A.; Mecrow, B.C.; Armstrong, M. Permanent-Magnet Flux-Switching Synchronous Motor Employing a Segmental Rotor. IEEE Trans. Ind. Appl. 2012, 48, 2259-2267. [CrossRef]

8. Al-Ani, M.M.J.; Jupp, M.L. Switched flux permanent magnet machine with segmented magnets. In Proceedings of the 8th IET International Conference on Power Electronics, Machines and Drives (PEMD 2016), Glasgow, UK, 19-21 April 2016.

9. Hua, W.; Cheng, M.; Zhang, G. A Novel Hybrid Excitation Flux-Switching Motor for Hybrid Vehicles. IEEE Trans. Magn. 2009, 45, 4728-4731. [CrossRef]

10. Lee, C.H.T.; Chau, K.T.; Chan, C.C. Comparison of Flux-Switching Machines with and Without Permanent Magnets. Chin. J. Electr. Eng. 2015, 1, 78-84.

11. Chen, J.T.; Zhu, Z.Q.; Iwasaki, S.; Deodhar, R.P. A novel E-core flux-switching PM brushless AC machine. IEEE Energy Convers. Congr. Expo. 2010, 3811-3818. [CrossRef]

12. Mcfarland, J.D.; Thomas, M.J.; EL-Refaie, A.M. Analysis of the Torque Production Mechanism for Flux-Switching Permanent-Magnet Machines. IEEE Trans. Ind. Appl. 2015, 51, 3041-3049. [CrossRef]

13. Zhu, Z.Q.; Howe, Y.P.D.; Iwasaki, S.; Deodhar, R.; Pride, A. Analysis of electromagnetic performance of flux-switching PM machines by non-linear adaptive lumped parameter magnetic circuit model. IEEE Trans. Magn. 2005, 41, 4277-4287. [CrossRef]

14. Heller, B.; Hamata, V. Harmonic Field Effects in Induction Machines; Elsevier: Amsterdam, The Netherlands, 1977; pp. 54-67.

15. Li, D.; Qu, R.; Li, J.; Xu, W.; Wu, L. Synthesis of Flux Switching Permanent Magnet Machines. IEEE Trans. Energy Convers. 2016, 31, 106-117. [CrossRef] 